\title{
ENSAIO SOBRE A HETERONORMATIVIDADE: MODOS CURRICULARES DE APRENDIZAGEM DAS SEXUALIDADES E DO GÊNERO
}

\section{ESSAY ABOUT HETERONORMATIVITY: CURRICULAR MODES OF LEARNING SEXUALITIES AND GENDER}

\author{
CAETANO, Marcio Rodrigo Vale \\ mrvcaetano@gmail.com \\ FURG - Universidade Federal do Rio Grande \\ GOULART, Treyce Ellen Silva \\ treyce.ellen@hotmail.com \\ FURG - Universidade Federal do Rio Grande \\ SILVA, Marlon Silveira da \\ marlon_ttbg@hotmail.com \\ FURG - Universidade Federal do Rio Grande
}

\begin{abstract}
RESUMO Esse ensaio segue o entendimento de que as identidades sexuais são marcadas pela cultura e, ao se apoiar nas perspectivas feministas e decoloniais, focaliza a possibilidade de reinvenção do sujeito. Contudo, reconhece que, independente das nossas trajetórias, intuímos por meio dos instrumentos que nos educaram, uma forma de ser, estar ou transitar nos marcadores político-sexuais "homem" e "mulher". Assim, buscaremos questionar os currículos com vista a interrogá-los sobre os discursos que produzem modos de subjetivação e que nos ensinaram formas heteronormativas complementares e assimétricas de projeção das identidades sexuais.
\end{abstract}

Palavras-chave: Currículo. Escola. Heteronormatividade. Sexualidade. Gênero.

ABSTRACT This essay theorizes sexual identities as shaped by culture and, from a feminist and decolonialist perspective, focuses on the possibility of reinventing the subject. However we recognize that, regardless of our trajectories, we intuit - by means of the instruments that educated us - a way of being, living and moving through life into political-sexual social categories of "man" and "woman". Thus, we aim to critique school curricula in a way which interrogates their discourses that produce modes of subjectivity as well as teach us about heteronormative, complementary and asymmetric ways of projecting sexual identities on society.

Key-words: School curricula. School. Heteronormativity. Sexuality. Gender.

\section{SEXUAL DO CORPO: ASPECTOS TEÓRICO-METODOLÓGICOS}


Atos de Pesquisa em Educação - ISSN 1809-0354

Blumenau - vol. 11, n. 2, p.634-655 ago./nov. 2016

DOI: http://dx.doi.org/10.7867/1809-0354.2016v11n2p634-655

Dados os espaços interativos, possuímos - em qualquer que seja o lugar em que vivemos - um entendimento do que seja homem ou mulher. Esta situação nos permite afirmar que atualmente o entendimento sobre o sexo está capilarizado. Ele criou e legitimou marcas e se tatuou nas corporalidades. Sua inscrição, ainda que fragilizada, encontra-se na divisão social do trabalho e constituição legal de vínculo afetivo-sexual. Essa visão, muitas vezes binária, é fruto dos instrumentos que nos educaram e que nos auxiliaram na construção singular de nossa ideia de masculino e feminino, os chamados gêneros. Uma vez que estas formatações afetam as formas como historicamente os coletivos de sujeitos/as têm estabelecido relações dentro dos sistemas democráticos, propomos com este ensaio algumas provocações aos modos como dinâmicas binárias e hierarquizantes tem se articulado nas noções de cidadania.

Todas as considerações permitem reafirmar o ensaio como uma dissertação pouco extensa, na qual o/a autora/pesquisador/a constrói o seu objeto através de um encadeamento de raciocínios lógicos e fundamentados que estruturam sua argumentação. Mary Rangel (2007) argumenta que do ponto de vista semântico, pode-se compreender o ensaio como uma dissertação mais curta e menos metódica do que um tratado formal e acabado. Esse desenho, em princípio, menos rígido e mais flexível de encaminhamento de análises e proposições que suscitam e sugerem continuidade, seja para confirmações, seja para questionamentos, encontra também respaldo em outros autores, a exemplo de Manuel da Costa Pinto (1998), quando se refere ao seu próprio estudo como "provisório e aberto".

Ainda, de acordo com o estilo ensaístico, a dissertação não se encerra nos limites de seus termos e proposições. Ao contrário, a inconclusão de um ensaio tem o especial valor de suscitar e sugerir outros prosseguimentos. Assim acontece com este ensaio, cuja temática se centra em debater a tríplice "gênero, sexualidade e currículo", constituindo-se numa sugestão ao debate aos/às pesquisadores/as, esperando-se persuadi-los/as a considerá-la em suas investigações e análises, seja para encontrar novas perspectivas, seja para confirmar ou refutar as que este ensaio Ihes oferece, através da construção de seus argumentos. Tendo feito esse esclarecimento, dividiremos o artigo em dois momentos. Em um primeiro exercício, 
Atos de Pesquisa em Educação - ISSN 1809-0354

Blumenau - vol. 11, n. 2, p.634-655 ago./nov. 2016

DOI: http://dx.doi.org/10.7867/1809-0354.2016v11n2p634-655

traremos à discussão alguns tensionamentos sobre as produções discursivas em torno de sexo e gênero. Em seguida, faremos algumas provocações sobre como os arranjos do eixo sexo-gênero-sexualidade estão implicados em relações de poder que afetam nossas performances afetivo-sexuais e os movimentos curriculares na escola.

Com usos distintos entre as correntes teóricas, o conceito de gênero não foi uma invenção feminista. Antes de Gayle Rubin utilizá-lo para analisar o tráfico de mulheres em 1975, ele já se encontrava na obra de Robert Stoller: Sex and Gender, publicada em 1968. A releitura deste conceito pelas feministas está inserida em momentos históricos de alterações sociais substanciais, a exemplo da inserção de mulheres brancas e de classes medianas no mundo do trabalho formal. Ao ponderar o sexo como questão a se explicar, em vez de entendê-lo como dado, o conceito de gênero trouxe ao plano prático-teórico-prático as diferenças sexuais na agenda de investigações acadêmicas e de elaboração de políticas públicas.

Como não bastasse, a emergência do conceito de gênero inscrevia-se em um processo que tornava visível uma relação social marcada pela desigualdade investigativa entre mulheres e homens. Ao retomar, em outros moldes, velhas questões (a exemplo da participação de mulheres nas decisões políticas ou sua presença nos grandes feitos da humanidade), o conceito de gênero deu lugar, mais recentemente, a uma perspectiva crítica sobre a produção dos saberes em diversas disciplinas das ciências.

Conforme podemos observar, a categoria de gênero reemerge com as feministas como um dispositivo para problematizar as desigualdades orientadas pelas diferenças sexuais e, sobretudo, como um contrato epistemológico para produzir conhecimento frente aos saberes hegemônicos que buscava justificativas para limitar a cidadania a determinados tipos de homens: proprietários, brancos, classe-média, heterossexuais e judaico-cristãos.

A palavra sexo é correntemente usada para designar o órgão anatômico sexual e a relação genital entre pessoas, incluindo ou não a penetração. Mas, nesse texto, iremos entendê-la como um feito social marcado pelo significado cultural. Se aceitarmos o entendimento sobre o corpo como uma situação cultural, então, a noção 
Atos de Pesquisa em Educação - ISSN 1809-0354

Blumenau - vol. 11, n. 2, p.634-655 ago./nov. 2016

DOI: http://dx.doi.org/10.7867/1809-0354.2016v11n2p634-655

de corpo e sexo natural se faz cada vez mais suspeita. Enquanto dispositivos de subjetivação e de governamento, entendemos que os discursos produzidos em torno do gênero e do sexo (re)produzem representações sociais, que uma vez construídos pela linguagem, ganham significado na cultura, subjetivando os sujeitos e, com isso, classificando-os.

Segundo Furlani (2005), "a representação é o modo como os significados, construídos e atribuídos pela retórica e pelo discurso, dão sentido e posicionam as diferenças, as identidades, os sujeitos, num processo que é fundamentalmente social, histórico e político". Daí a importância de pensá-las (as representações) enquanto categorias produzidas e inventadas. Mais do que isso, questionar aqueles que falam, por que falam e de onde falam ao produzirem uma determinada identidade. A respeito deste aspecto, Silva (1999) ressalta:

Tanto a educação quanto a cultura em geral estão envolvidas em processos de transformação da identidade e da subjetividade. (...) através dessa perspectiva, ao mesmo tempo que a cultura em geral é vista como uma pedagogia, a pedagogia é vista como uma forma cultural: o cultural torna-se pedagógico e a pedagogia torna-se cultural (SILVA, 1999, p. 139).

Sendo assim, entende-se que, se não existe uma essência "natural" sobre o gênero, tampouco existe sobre o sexo e, muito menos, sobre as sexualidades. O que se tem são construções discursivas que, ao serem criadas histórica e culturalmente, estabelecem performances sociais aceitáveis para o que entendemos e assimilamos como homem e mulher. Da mesma forma, será elaborado performances para aqueles/las que se opuserem à essas performatividades normativas, como no caso dos/das homossexuais.

Uma das grandes contribuições da filósofa estadunidense Judith Butler, pode se dizer, foi trazer a própria biologia para o campo das construções sociais.

Embora segundo Beauvoir nos 'tornemos' nossos gêneros, o movimento temporal desse tornar-se não segue uma progressão linear. A origem do gênero não é temporalmente descontínua precisamente porque o gênero não é originado de repente em algum ponto do tempo depois do que assume forma definitiva. Sob importante aspecto, o gênero não é historiável a partir de uma origem definível porque, por sua vez, é uma atividade originante que 
Atos de Pesquisa em Educação - ISSN 1809-0354

Blumenau - vol. 11, n. 2, p.634-655 ago./nov. 2016

DOI: http://dx.doi.org/10.7867/1809-0354.2016v11n2p634-655

acontece sem cessar. Já não mais entendido como um produto de antigas relações culturais e psíquicas, o gênero é um modo contemporâneo de organizar normas passadas e futuras, um modo de nos situarmos e através dessas normas, um estilo ativo de viver nosso corpo no mundo (BUTLER, 2003a, p. 142).

É importante ressaltar também que, no cerne desta contínua atividade originante citada por Butler, também encontra-se as configurações hierarquizadas entre as mulheres. Se nos debruçamos sobre as colonialidades, ou seja, as continuidades nas relações de poder engendradas após o fim do colonialismo oficial, é necessário considerar a racialização e generificação enquanto fatores que contaminam e determinam tais relações. Sendo assim, o que buscamos apontar com esta provocação é que nosso colonialismo e nossa colonialidade nos denunciam, a partir da construção ativa da desumanidade de negras e indígenas, em contraponto, a afirmação do gênero apenas às mulheres brancas.

Nestes termos, o diformismo sexual aplicado a indígenas e negras/os nos informa sobre o sexo enquanto construção discursiva e atravessada de outras representações. Então, com este diálogo, pensamos que tanto gênero como o sexo parecem ser questões culturais. Se o corpo, seu sexo e sexualidade são ficções, isso parece nos dizer que sexo foi gênero todo o tempo (BUTLER, 2003a) e que para sua performance é exigido o mínimo de liberdade para excitar a criatividade.

Com a liberdade criativa, a sexualidade fala muitas linguagens, se dirige a muitos tipos de pessoas e oferece uma cacofonia de distintos valores e possibilidades (WEEKS, 1998). Com elas, os sujeitos e instituições são capazes de inventar identidades, desejos, práticas, que acabam por fragilizar qualquer certeza e nos denunciam que mesmo com toda a tentativa de regular, de domesticalizar os corpos ou determinar as práticas pedagógicas em situação de liberdade, o sujeito é mais rizomático.

A liberdade nos aproxima da compreensão de Foucault (1997) quando nos convida a refletir sobre o poder como algo que permeia todas as relações, ou seja, está difundido e capilarizado nelas. O poder entendido a partir de práticas ou de relações implica também práticas de resistência, não a partir de um lugar privilegiado, 
Atos de Pesquisa em Educação - ISSN 1809-0354

Blumenau - vol. 11, n. 2, p.634-655 ago./nov. 2016

DOI: http://dx.doi.org/10.7867/1809-0354.2016v11n2p634-655

mas exercida dentro das diferentes redes de relações entre sujeitos/as e instituições. Ou seja, onde há poder, existe possibilidades de resistência.

Para Foucault (1997), saber e poder inserem-se em uma mesma relação, em que nem todo saber detém o poder, e nem todo o poder detém o saber, mas para o poder funcionar é necessário acionar os chamados regimes de verdades. Dito de outro modo, é necessária a produção de uma série de discursos que estabeleçam "a verdade", e que vão autorizar que certas coisas sejam ou não pensadas e ditas.

Sendo assim, a produção dos saberes e a produção "da verdade" estão diretamente ligadas ao exercício de poder, da mesma forma que o poder não pode ser exercido sem a produção desses saberes. Logo,

\begin{abstract}
Nenhum saber se forma sem um sistema de comunicação, de registro, de acumulação, de deslocamento, que é em si mesmo uma forma de poder, e que está ligado, em sua existência e em seu funcionamento, às outras formas de poder. Nenhum poder, em compensação, se exerce sem a extração, a apropriação a distribuição ou a retenção de um saber. Nesse nível, não há o conhecimento, de um lado, e a sociedade, do outro, ou a ciência e o Estado, mas as formas fundamentais do "saber-poder" (FOUCAULT, 1997, p. 19).
\end{abstract}

Nessa direção, é necessário pensarmos o poder para além da relação entre indivíduo e um saber específico, mas o indivíduo inserido em um contexto de população, sendo parte de um corpo social. Por isso, a sexualidade é tão temida e é capaz de gerar tantos discursos na escola, na ciência, na religião; sua estreita relação com a liberdade amedronta as pobres almas da arrogância porque fragiliza suas verdades e certezas. "A sexualidade não segue as regras da cultura, mesmo quando a cultura tenta domesticar a sexualidade. Podemos insistir que a sexualidade é a própria alteridade" (BRITZMAN, 2001, p. 89. Tradução livre).

\title{
2 CRIAÇÃO E TENSÃO COM A ESCOLA
}


Atos de Pesquisa em Educação - ISSN 1809-0354

Blumenau - vol. 11, n. 2, p.634-655 ago./nov. 2016

DOI: http://dx.doi.org/10.7867/1809-0354.2016v11n2p634-655

Alguns sujeitos argumentam que sexualidade não se configura nos currículos e que, portanto, ela não se encontra entre as prioridades da escola. Essa afirmação nos revela duas situações: o desconhecimento das relações e práticas cotidianas da escola e as dimensões assumidas do conceito de sexualidade.

A situação em que se encontra o eixo gênero-sexualidade na escola favorece os movimentos heteronormativos, as tensões curriculares e acaba por consolidar a sexualidade como uma scientia sexualis ${ }^{1}$, como nos descreve Foucault (1988). $\mathrm{Na}$ perspectiva do autor, haveria duas formas de apropriação da sexualidade por saberes, uma via scientia sexualis, como já dito, e outra através da ars erotica. Enquanto que, na última, o prazer, a curiosidade e a subjetividade encontram-se na agenda de discussão e na experiência, para a anterior, a narrativa seria conduzida pela cientificidade com ênfase na preocupação com a reprodução. Cotidianamente, ambas estão presentes e se tensionam nos movimentos curriculares, entretanto, dada a forma moderna de organização da escola é indiscutível que a scientia sexualis goza de maior prestígio e reconhecimento escolar.

Esta situação nos faz recordar que quando a sexualidade se converte em objeto do conhecimento e que, por sua vez, suas metáforas científicas são aplicadas à população, ela gera outros movimentos de subalternidades e de controles.

\begin{abstract}
Quando tentamos mapear a geografia do sexo [...] ou quando tentamos ler a sexualidade através de uma teoria favorita, um manual de instrução ou de acordo com as visões dos chamados especialistas. Quando inserida no currículo escolar ou na sala de aula universitária - quando digamos, a educação, a sociologia, a antropologia colocam sua mão na sexualidade - a linguagem do sexo torna-se uma linguagem na sexualidade - a linguagem do sexo torna-se uma linguagem didática, explicativa e, portanto, dessexuada.
\end{abstract}

\footnotetext{
1 Segundo Foucault (1988), a scientia sexualis (correspondente ao Ocidente) teria se desenvolvido a partir do século XIX com a função de controlar os corpos de homens e mulheres. Tal controle, inicialmente era exercido pelo ato da confissão (poder pastoral), em que a religião se tornava peça fundamental nesse processo. Posteriormente, no século $\mathrm{XX}$, a confissão foi substituída pela medicina, onde a Ciência (mais precisamente as Ciências da Saúde) foi a autorizada a exercer a "verdade" sobre o sexo, instituindo o certo/errado, o normal/anormal. Foi por essa Ciência e o poder a ela atribuído (poder disciplinar) que nosso sexo foi regulado através dos saberes por ela produzido e difundidos através de seus discursos sobre os corpos, na maioria das vezes naturalizando práticas e comportamentos.
} 
Atos de Pesquisa em Educação - ISSN 1809-0354

Blumenau - vol. 11, n. 2, p.634-655 ago./nov. 2016

DOI: http://dx.doi.org/10.7867/1809-0354.2016v11n2p634-655

Mais ainda: quando o tópico do sexo é colocado no currículo, nós dificilmente podemos separar seus objetivos e fantasias das considerações históricas de ansiedades, perigos e discursos predatórios que parecem catalogar certos tipos de sexo como inteligíveis, enquanto outros tipos são relegados ao domínio do impensável e do moralmente repreensível (BRITZMAN, 2001. p. 90).

Se contemplarmos a sexualidade como dimensão da curiosidade, conforme nos propõe Britzman, é possível ampliar o conteúdo sobre a sexualidade, ao invés de limitá-la ao ato sexual e, por sua vez, à reprodução dos seres humanos. Se assim a vemos, o debate sobre ela se estenderá a toda a vida escolar.

Este ponto de reflexão nos leva novamente ao conceito do erótico proposto por Audre Lorde e discutido diretamente no âmbito da educação, como bell hooks. Conforme a primeira autora feminista, o erótico tem sido frequentemente distorcido em pornográfico, o que para a autora é exatamente o oposto do que se propõe a prática do erotismo. Para Lorde (1984), o erótico é a medida entre o senso de si e o caos do mais forte sentir.

Temos tentado separar o espiritual e o erótico, assim reduzindo o espiritual a um mundo de afetos insípidos, um mundo do asceta que deseja sentir nada. Mas nada está mais longe da verdade. Pois a posição ascética é uma do mais grandioso medo, da mais grave imobilidade. A severa abstinência do asceta torna-se a obsessão dominadora. E não é uma de autodisciplina mas de autoabnegação. A dicotomia entre espiritual e político é falsa também, resultante de uma atenção incompleta ao nosso conhecimento erótico. Pois a ponte que os conecta é formada pelo erótico- o sensual-, aquelas expressões físicas, emocionais e psíquicas do que é mais profundo e mais forte e mais rico dentro de cada uma de nós, sendo compartilhado: as paixões de amor, em seus mais fundos significados (LORDE, 1984, p. 2).

Ao vivermos/buscarmos a completude dessa profundidade, é afetada a forma como nos relacionamos com/nesse mundo.

A compreensão de que o Eros é uma força que auxilia o nosso esforço geral de autoatualização, de que ele pode proporcionar um fundamento epistemológico para entendermos como sabemos o que sabemos, habilita tanto os[as] professores [as] e alunos [as] a usar essa energia na sala de aula de maneira a revigorar as discussões e excitar a imaginação crítica (HOOKS, 2013, p. 258). 
Atos de Pesquisa em Educação - ISSN 1809-0354

Blumenau - vol. 11, n. 2, p.634-655 ago./nov. 2016

DOI: http://dx.doi.org/10.7867/1809-0354.2016v11n2p634-655

Por essa razão é que "um dos princípios centrais da pedagogia crítica feminista é a insistência em não ativar a cisão entre mente e corpo [...] [o que] nos permite estar presentes por inteiro [...] na sala de aula." (HOOKS, 2013, p. 256). O erótico, nestes termos é a personificação do poder criativo, de uma energia criativa empoderada.

O erótico e o erotismo, entretanto, não estão desconectados dos discursos sobre sexo, gênero e sexualidade e, tampouco das interpelações raciais. Quando Lorde (1984) faz a crítica com relação à pornografização da energia erótica, apontando a exploração e ausência de agenciamento implicada neste processo, está nos incitando a pensar as adjacências desta distorção. Uma das facetas deste prisma reflete as noções de heteronormatividade que sugerem a necessária existência de uma hierarquia, de um desajuste entre os poderes das/os sujeitos envolvidos em uma relação afetivo-sexual.

Outra faceta deste prisma, correlata a essa, é que, quando nos debruçamos sobre os corpos femininos esses têm, constantemente, sua energia erótica por um lado enquanto algo a ser controlado, normalizado em direção à satisfação de corpos masculinos. Neste cenário, a hipersexualização da mulher negra, por exemplo, constrói seu corpo enquanto público, violável. Por outro lado, há também os discursos que direcionam esta mesma energia em relações de cuidado com os outros. Tanto uma representação quanto a outra implica homens e mulheres em interações obrigatórias e desiguais, que buscam todo o tempo aprisioná-las/os à reprodução da coerência de sexo-gênero-sexualidade e os papeis sociais decorrentes desta. Sendo assim, o projeto de indivíduo subjacente a esta norma, o/a enquadra em uma relação sempre dicotômica e atomizada, e o erótico subverte esta construção.

Se o corpo é território, é relevante considerá-lo enquanto contestado, sempre em disputa e disputado, produtor e produto de discursos. Com Goellner (2007), temos que o corpo é provisório, conjuntural e histórico, ou seja, não natural. Sendo a naturalidade do corpo um estatuto a ser criticado são também as falas produzidas com/por/sobre ele. Interrogar os discursos sobre o corpo é salientar sua geração de hierarquizações quando definem o que é positivo, o que é belo, jovem e saudável. Tais definições, com Foucault (1987), são atravessadas por relações de poder que 
Atos de Pesquisa em Educação - ISSN 1809-0354

Blumenau - vol. 11, n. 2, p.634-655 ago./nov. 2016

DOI: http://dx.doi.org/10.7867/1809-0354.2016v11n2p634-655

buscam tornar estes corpos úteis, produtivos, docilizados, inteligíveis dentro de uma lógica dicotômica e normativa.

Estes atravessamentos se dão por meio de métodos disciplinares: "um conjunto de saberes e poderes que investiram no corpo e nele se instauraram" (GOELLNER, 2007 , p. 35). Estes métodos encontram-se balizados nos discursos produzidos nas mais diversas instâncias, tais como ciência, escola, família, mídia, etc. As noções de beleza, juventude, masculinidade, feminilidade (entre outras) que incidem sobre este corpo são referentes, localizadas e foram se transmudando, incorporando outros conceitos com o passar do tempo. Sendo assim, com Goellner afirmamos que o corpo, assim como as configurações anatômicas que definem/produzem culturalmente homens e mulheres (entre outras categorias de diferenciação), deve ser considerado enquanto categoria discursiva e, portanto, historicizada.

Com este entendimento, partimos do princípio que transitam modelos de gêneros nos currículos e estes projetam a heterossexualidade e a masculinidade hegemônica ${ }^{2}$ como norma e referência. Não estamos com isso atribuindo à escola o poder e, tampouco, a responsabilidade de explicar as identidades, nem muito menos de determiná-las. Porém, reconhecemos que as proposições e interdições realizadas pelas escolas fazem e produzem sentidos, além de possuir "efeitos de verdade" nos sujeitos (CAETANO, 2011).

De forma mais ampla, o conjunto de discursos ou teorias do currículo deduzem o tipo de conhecimento considerado importante a partir de descrições sobre o tipo de sujeito que devem constituir a sociedade. Cada "teoria" leva, em si, para determinado "modelo" de sujeito e corresponde a determinados tipos de saberes presentes na organização curricular. Entendemos currículos como as tecnologias pedagógicas (arquitetura, livros didáticos, vestimentas, mídia, etc.), que, significadas na cultura e obedecendo a certa lógica de planejamento, constroem, ensinam e regulam

\footnotetext{
${ }^{2}$ Pensar em masculinidade hegemônica é se ancorar em algo criado, construído, imaginado, considerado como padrão e disseminado pelas experiências e pelos discursos e que, a cada momento, busca ser consolidado nas performances significadas como masculinas. O que quero dizer, é que independente do contexto social, histórico e cultural, todos nós intuímos, por meio das práticas educativas que nos formam, uma forma de ser masculino. Essa, por sua vez, é configurada, quase sempre, na negação do que é significado como feminino.
} 
corporalidades, produzindo modos de subjetivação e arquitetando formas e configurações de estar e viver na escola e, mais amplamente, na sociedade.

Como parte das instituições que interagem e se integram na sociedade, a escola tem, em seu interior, sujeitos que trazem de suas relações mais amplas os saberes que se configurarão nos currículos. Isto significa assumir que a escola se caracteriza como espaço privilegiado de encontro de diversas leituras e conhecimentos do mundo. Assim, os currículos, ainda que ausentes de reflexão, não são ações neutras sem resultados práticos na vida dos sujeitos. Eles são configurados por sistemas de interesses, sejam estes elaborados pelos sujeitos que estão diretamente nas práticas escolares ou por aqueles que na gestão orientam/determinam o que deve ser ensinado na escola.

Pensado de outra forma, ao não problematizar em suas agendas, planos e conteúdos o quanto somos sujeitos construídos histórico e culturalmente, a escola já está produzindo e regulando as condutas sexuais dos/das alunos/as. Isso se dá, sobretudo porque aquilo que não é dito, o silenciado, também corrobora no processo de subjetivação dos corpos, na maioria das vezes, baseado em concepções binárias, assimétricas e complementares entre a mulher e o homem: a heterornormatividade.

A heteronormatividade não somente almeja manter a lógica dicotômica e complementar entre homens e mulheres, como também a degradação social dos sujeitos que buscam subvertê-la. Neste sentido, a homofobia e o machismo são respostas da heteronormatividade destinada às sexualidades dissidentes ou às mulheres. O sistema heteronormativo, para se manter na ordem das coisas, necessita se retroalimentar da lógica sexual binária. Daí a necessidade de ideologicamente controlar as tecnologias pedagógicas da escola e mais amplamente da cultura. Nestes pressupostos, articulam-se as identidades e as práticas curriculares.

A homofobia ultrapassa as expressões do corpo e as práticas sexuais desdobram-se nas identidades de gênero. Isto nos leva a afirmar que somos todos os dias interpelados por determinações regulamentares que nos ensinam sobre como devemos avaliar, classificar e hierarquizar os sujeitos, produzindo, em última instância, relações assimétricas heterocentradas. Os sistemas normativos operam 
Atos de Pesquisa em Educação - ISSN 1809-0354

Blumenau - vol. 11, n. 2, p.634-655 ago./nov. 2016

DOI: http://dx.doi.org/10.7867/1809-0354.2016v11n2p634-655

verdades nos discursos e produzem modos de subjetivação que funcionam como marcos regulatórios de nossos comportamentos e miradas sobre o mundo.

A heteronormatividade se conecta diretamente com o androcentrismo. Em primeiro plano, sustenta a ideia do governo homem/masculino sobre a mulher/feminino. Em segundo lugar, ao exigir a tarefa de governo do homem e de governada da mulher, Ihes obrigam a relações intrínsecas e reprodutivas do sistema em uma lógica binária. Nestes termos, penso que qualquer que seja a análise ou ativismo político das identidades sexuais que não considere estes dois conceitos, estará reduzindo e limitando suas ações à superficialidade, sem contar, que estará reproduzindo cadeias de governos, alimentando a manutenção das estruturas que abarcam um ou ambos os conceitos (CAETANO, 2011; CAETANO; DE GARAY, 2012).

As práticas educativas heteronormativas são tão inexpressivas que raramente as questionamos. A partir dos ensinamentos deixados por Monique Wittig (2006) sobre o papel político das categorias mulher e homem ${ }^{3}$, deveríamos nos interrogar sobre a oposição binária entre a heterossexualidade e a homossexualidade. $\mathrm{O}$ ideal de homem universal foi efeito de interesses políticos que buscou estabelecer ao longo

\footnotetext{
${ }^{3}$ Para Wittig, a heterossexualidade seria um regime político sustentado pela submissão e apropriação das mulheres em que, a partir de sua capacidade biológica para gerar filhos/as, procriar, é colocada num lugar de subordinação, ou seja, a submissão está atrelada à categoria de sexo: "naturaliza-se a história e se passa a crer que homens e mulheres sempre existiram e sempre existirão do mesmo modo" (WITTIG, 1992, p. 10-11). Através da naturalização destes fenômenos, justifica-se o lugar de submissão das mulheres. Compreender o conceito de não-mulher nessa perspectiva, passa antes pela compreensão de que a categoria "sexo" é uma categoria política que funda a sociedade enquanto heterossexual. Em outras palavras, a categoria sexo estabelece como natural a relação que está na base da sociedade (no caso, heterossexual) inclusive, economicamente (divisão sexual do trabalho) e sobretudo no campo do desejo. Tal categoria é o produto que impõe às mulheres a obrigação absoluta de reproduzir a sociedade heterossexual (WITTIG, 1992). Nela, o contrato do matrimônio torna-se uma das formas pelas quais os homens se "apropriam" das mulheres (por lei) e se fazem homens, assim como as mulheres se constituem em um par complementar e assimétrico intrínseco, uma vez que a esposa pertence ao marido enquanto pessoa física, tendo que trabalhar sem remuneração, sujeita à violência sexual e doméstica, entre outras formas de violência e dominação masculina. Sendo assim, a categoria sexo é o que a autora chama de totalitária, pois é legitimada por instituições como o Direito, a Medicina e outras tão tradicionais, tanto que, através de seus discursos biologizantes sobre a natureza dos corpos, exerciam (e ainda exercem) influencia na divisão binária homemmulher.
} 
Atos de Pesquisa em Educação - ISSN 1809-0354

Blumenau - vol. 11, n. 2, p.634-655 ago./nov. 2016

DOI: http://dx.doi.org/10.7867/1809-0354.2016v11n2p634-655

da história uma hegemonia branca, proprietária, adulta e heterossexual, bem como a categoria "mulher" como o outrem desse homem.

A homossexualidade vem sendo um corpo discursivo alimentado pela lógica heteronormativa e se caracterizando como o outrem da heterossexualidade. Torna-se necessário atentar para uma alteração político-epistemológica e subjetiva que efetivamente destitua a lógica binária e seus efeitos sobre o conhecimento e, por sua vez, dos currículos.

Foucault, ao criticar a configuração binária de poder e o modelo jurídico de opressor e oprimido, nos oferece algumas estratégias para a subversão da hierarquia de gênero e ao binarismo homo/hétero. Sua tática, se assim podemos chamá-la, não é transcender as relações de poder, mas multiplicar suas diversas configurações de tal modo que o modelo jurídico de poder como opressão e regulação deixe de ser hegemônico. Para Butler (2003), essa proliferação auxiliaria no processo de desconstrução dos sistemas de dominação, uma vez que os sistemas essencialistas que sustentam o gênero atuam e mascaram os discursos dominantes, tornando-se elementos de opressão. Talvez, desse ensinamento deixado por Foucault, possamos retirar as bases para proliferar inúmeras e ilimitadas formas de ser homem e mulher, a tal ponto que nenhuma seja a "legítima forma" e, tampouco, alguma hegemonicamente governe o fazer da/na escola.

Parafraseando Deborah Britzman (2005), o direito à liberdade de exercer a sexualidade e a inventar o gênero se compõe de pequenas ações cotidianas, mas de profundo significado na organização sócio-política: o direito a inventar o Ser como possibilidade, a elaborar e executar o que the der prazer e constituir de forma singular - Estar no mundo, a dignidade, a informação adequada às necessidades, a formulação de infinitas perguntas e a obtenção de perguntas como respostas, a adesão ao que socialmente the fascina, a curiosidade sobre o desconhecido e, sobretudo, o direito de amar e com o amor transformar os dogmas do corpo e, com o corpo, o mundo.

Se nos aproximamos de Lorde (1984), encontramos a necessária ênfase na capacidade de gozar (com e para além de nossas práticas sexuais) como também 
Atos de Pesquisa em Educação - ISSN 1809-0354

Blumenau - vol. 11, n. 2, p.634-655 ago./nov. 2016

DOI: http://dx.doi.org/10.7867/1809-0354.2016v11n2p634-655

prática de liberdade. O erótico, nestes termos, nos desconforma frente ao conveniente e, ao mesmo tempo, nos desafia à busca constante de uma mudança genuína para além das reacomodações de personagens e relações de poder.

A conquista destes coletivos de direitos exige condições básicas de vida o que nos leva assumir a sexualidade como princípio subjetivo de profundas dimensões políticas: comida, roupa, moradia, educação escolar, saúde, democracia, prazer, cidadania, liberdade, autoestima e satisfação... vida. Uma democracia sexual necessariamente implica um processo mais amplo de democratização em que seja desmantelado definitivamente as barreiras que restringem o potencial e o crescimento individual, tais como: a exploração econômica, a opressão racial e a desigualdade de gênero, o autoritarismo moral e desigualdade de acesso à educação. Isto não implica que desaparecerão ou deveriam desaparecer as dificuldades, as necessidades e interesses, os conflitos de prioridade e de desejo. Ao contrário, a meta seria o de obter o máximo de meios pelos quais estas diferenças e conflitos possam se resolver democraticamente (WEEKS, 1998).

Quando observamos nossas especificidades coloniais, mais de vinte anos após o restabelecimento das democracias neoliberais, as/os sujeitas/os (ex)cêntricos dos chamados novos ${ }^{4}$ movimentos sociais de esquerda vêm pautando sua exclusão dentro da democracia. Para Breny Mendoza, o cerne desta discussão sobre a democracia jaz na própria edição deste conceito e, portanto, a autora parte da premissa de que existe uma colonialidade da democracia.

Ao analisar criticamente, com María Lugones (2011), as teorias decoloniais, sobretudo a partir de Aníbal Quijano, Mendoza sublinha a naturalização das relações de gênero e da heterossexualidade na obra do autor peruano. Para Breny, as mulheres foram, a um só tempo, racializadas e inventadas como "mulheres", de acordo com princípios e códigos discriminatórios. Portanto, a colonização foi

\footnotetext{
${ }^{4}$ É corrente a divisão histórica entre aqueles movimentos sociais, considerados tradicionais, enquanto aqueles pautados nos embates causados pela questão de classe. O novo referido aqui, talvez não tenha nada de novidade, uma vez que visa dar conta daqueles/as sujeitos/as cuja diferença tem sido significada em termos de desigualdade e que historicamente vem tensionando as normatividades etnicorraciais e de gênero, entre outras.
} 
Atos de Pesquisa em Educação - ISSN 1809-0354

Blumenau - vol. 11, n. 2, p.634-655 ago./nov. 2016

DOI: http://dx.doi.org/10.7867/1809-0354.2016v11n2p634-655

acompanhada necessariamente pela racialização e colonialidade de gênero enquanto bases para a classificação social dentro daquele sistema. Sendo assim, o que as autoras nos propõem é que a ideia de gênero se produz concomitantemente com a ideia de raça.

Nestes termos, quando pensamos as relações coloniais de gênero e raça nas colônias, temos que às/aos escravizadas/os negras/os e indígenas, o que era aplicado aproximava-se mais a um diformismo sexual (macho e fêmea) ${ }^{5}$, o que demarcava a produção destes corpos como não humanos. Sendo assim, estas relações colonizadas de gênero e raça estiveram imbricadas e refletidas nas relações sociais de capital e trabalho que se engendraram a partir da experiência colonial. Nas relações desenvolvidas, foi forjada, consideravelmente a partir de diferenças fenotípicas, a codificação das diferenças e a noção de superioridade branca e masculina, frente aos povos indígenas e, posteriormente aos negros e amarelos. $\mathrm{O}$ autor descreve um cenário colonial em que a dominação/exploração estava diretamente ligada ao binômio raça/trabalho. Nestes termos, com a divisão racial do trabalho, e a partir da expansão mundial (propiciada por séculos de exploração de trabalho gratuito de negros/as e indígenas) da dominação colonial, por parte da dita raça dominante, foi imposto o mesmo critério de classificação social a toda a população mundial em escala global.

Daí depreende-se e relacionam-se ideais eurocêntricos de modernidade para a concepção do mundo em que, em primeiro plano, a história da civilização humana é retratada como uma trajetória que parte de um estado de natureza e culmina na Europa; e, em segundo plano, são outorgadas enquanto diferenças de natureza (racial) e não de história do poder, as diferenças entre europeus e não europeus. Dessa maneira, legitimava-se a dicotomização e a essencialização identitária. É o que Santos (2007) afirma enquanto "simetria dicotômica", que, ainda que pareça simétrica, esconde uma hierarquia e busca manter a racionalidade refém da ideia de totalidade e complementaridade.

\footnotetext{
${ }^{5}$ É importante ressaltar que, conforme Mendoza e Lugones, as "mulheres" escravizadas foram moeda de troca neste processo e garantiram aos "homens" escravizados manter algum tipo de poder e margem de manobra dentro deste sistema de exploração.
} 
Atos de Pesquisa em Educação - ISSN 1809-0354

Blumenau - vol. 11, n. 2, p.634-655 ago./nov. 2016

DOI: http://dx.doi.org/10.7867/1809-0354.2016v11n2p634-655

Deste modo, não é possível pensar o sul sem o norte, a mulher sem o homem, o escravo sem o amo. E dessa forma, é gerada a invisibilização, a produção ativa da não-existência daqueles/as que se encontram em posição inferior nesta hierarquização naturalizada. Assim, o primeiro componente é apresentado como o puro, ideal a ser alcançado, o modelo a ser copiado, a razão, enquanto ao segundo resta a cópia, a incompletude, a animalidade, a natureza. Estas categorias têm uma construção identitária relacional, e, portanto, sempre atrelada a seu "oposto".

Se retornamos à Mendoza e Lugones (2011), o que as autoras nos demarcam é que jaz na constituição do conceito democrático um duplo pacto. De um lado, um pacto social que deu conta de garantir as atividades assalariadas apenas aos homens brancos a partir das noções de superioridade natural branca, em detrimento dos trabalhadores escravizados não-brancos. E, outro, de gênero entre os homens. $O$ primeiro contrato livrou os homens brancos pobres da escravização, o segundo, do trabalho e circunscrito ao âmbito doméstico. Tal formatação social esteve diretamente implicada na concepção de cidadão livre, pleno em direitos, o sujeito/agente da democracia liberal e, para Mendoza, reflete a confluência do sistema heterossexista, de gênero colonial com o capitalismo e a democracia liberal.

Tais confluências seguem a se engendrar e retroalimentar dentro daquilo que cotidianamente chamamos democracia. Sendo assim, o passado e presente deste constructo social nos apontam para a análise de que, mesmo em sua composição, já nos informa quais são seus interlocutores e sujeitos a quem se destinam suas estruturas. Se assim o interpretamos, será o caminho da legalidade, a exigência da inclusão/adequação/assimilação dentro deste sistema um caminho possível ou menos violentador do que a outra opção? Existirão também para nós negras/os, gays, lésbicas, travestis e transexuais apenas possibilidades atomizadas de existência/resistência? Será a "passabilidade" de algumas/uns suficientemente satisfatória para acreditarmos em avanços e profundas transformações do estabelecido como realidade?

Para além de qualquer tentativa de responder a estas questões, parece-nos necessário que não abandonemos a inquietação e a crítica mesmo às nossas 
Atos de Pesquisa em Educação - ISSN 1809-0354

Blumenau - vol. 11, n. 2, p.634-655 ago./nov. 2016

DOI: http://dx.doi.org/10.7867/1809-0354.2016v11n2p634-655

conquistas. Se atualmente, tem se alargado e democratizado diversas instâncias de ação política, é aconselhável a percepção de que nem todas/os cabem nesta cidadania. Talvez, nem todos/as queiramos caber.

As instituições midiáticas familiares, religiosas, escolares, entre outras não encontram-se isentas na (re)construção destes conceitos. A cultura escolar e as necessidades políticas nos sugerem uma relação com os movimentos curriculares, as ações pedagógicas e as necessidades sociais mais amplas dos sujeitos. Pensando com Foucault (1988, 2005, 2006), a sexualidade "ars erotica" está mais próxima da liberdade que permite a construção de sentidos e usos do que dos currículos prescritos pela "scientia sexualis". A primeira está mais presente nos movimentos e fazeres curriculares do que nos programas governamentais e nas ações nãogovernamentais que buscam codificá-la ou estabelecer verdades sobre ela.

A sonhada liberdade ou a opção de criar novos tipos de liberdade e novas questões à vida são a base que nos implusionam a subverter a sociedade democrática e, para então, nos reapropriarmos da possibilidade de construir infinitamente o conceito de cidadania, de modo a ajustá-lo às necessidades dos coletivos de sujeitos. Como na política e na cultura, a sexualidade é o lugar do impossível, é o espaço em que o sujeito deixa suas contribuições e se torna autor de sua prática e invenção. Com ela, em situações democráticas, o fim da vida é o limite da criação e da invenção de si.

A incompletude da sexualidade nos faz refletir a cidadania porque esta última não consiste em receber sem postular um ato no qual os sujeitos deixam suas contribuições às necessidades sociais, ao pensamento e à eleição de estilos de vida. Entretanto, a eleição implica, em primeiro lugar, democracia. Pode parecer estranho aplicar a palavra "democracia" ao âmbito sexual, porém, sem dúvida, se necessita um novo conceito de democracia quando falamos do direito a controlar nossos corpos, quando decidimos que nossos corpos são de nossa "propriedade".

Nessa direção, somos interpelados/as a repensar a democracia, sobretudo a partir de uma visão decolonial, para além da compreensão comum de espaço de participação, uma vez que, da forma como está, ela cerceia e regula (inclusive através 
Atos de Pesquisa em Educação - ISSN 1809-0354

Blumenau - vol. 11, n. 2, p.634-655 ago./nov. 2016

DOI: http://dx.doi.org/10.7867/1809-0354.2016v11n2p634-655

da própria inclusão tão reivindicada pelo próprio movimento LGBT), de diferentes formas, as condutas e os desejos dos sujeitos.

Como na política e na cultura, a sexualidade é o lugar imaginativo em que se reúnem os discursos sociais mais amplos. Porém, na cultura, na política e na sexualidade também coexistem espaços onde se abre a possibilidade de romper os significados, refazer os interesses, buscar as ideias e onde a inconformidade pode possibilitar outras configurações de estar no mundo. Nesta ceara, concordamos com Donna Haraway (2000) quando a autora defende que, a partir destas configurações, é necessária a sutil compreensão das possibilidades trazidas pelos poderes emergentes e que tem potencial para mudar as regras do jogo. Ainda que estejamos distantes de compreender/empreender plenamente o alcance da interseccionalidade, por exemplo, precisamos reconhecer e potencializar os saberes produzidos pela perspectiva parcial que permite novas e criativas interpretações, assim como outras formas de participação política.

Ainda que o mundo exista sem a nossa presença, nossa presença no mundo nos exige muita criatividade para inventá-lo. Para que o mundo tenha sentido devemos criar/significar o que já contém, devemos aprender a questioná-lo e a inventar o que ainda não existe em nossas petições no mundo. Neste sentido, viver criativamente é também uma condição para criar/ampliar a democracia e se criar com a democracia.

\section{CONSIDERAÇÕES FINAIS}

Se por um lado, as discussões em torno do eixo sexo-gênero-sexualidade, por vezes, são cotidianas na academia e demais espaços de produção do conhecimento, por outro, temos a resistência a essas discussões nos currículos e demais instâncias educativas, demonstrando o quanto esses espaços são palco de disputas e tensionamentos políticos.

Como sabemos, o currículo é o instrumento escolar que visualiza o corpo como a superfície em que ele escreve ou imprime os valores culturais. Neste sentido, os 
Atos de Pesquisa em Educação - ISSN 1809-0354

Blumenau - vol. 11, n. 2, p.634-655 ago./nov. 2016

DOI: http://dx.doi.org/10.7867/1809-0354.2016v11n2p634-655

movimentos curriculares que se realizam nos cotidianos não são elementos inocentes e neutros de transmissão desinteressada de conhecimentos, mas construídos nos interesses que são eleitos pelas escolas, pelos sistemas educativos e, sobretudo, pelos e pelas professoras. Inúmeras pedagogias que envolvem a complexidade das identidades apontam para a noção de que os/as sujeitos/as, ao longo do seu desenvolvimento físico e psíquico, através das mais diversas instituições e ações sociais, se constituirão como homem e mulher em etapas que não são sequenciais, contínuas ou iguais e que de modo algum serão concluídas.

Esta configuração emerge porque os campos histórico-culturais que formam os sujeitos são implicados de conflitos e são capazes de produzir múltiplos sentidos, que nem sempre são convergentes nas noções de gêneros ou identidades sexuais. Conhecimentos fixos, universais e a-históricos são simplistas porque as performances de gênero destacam as pluralidades de etapas pelas quais as culturas constroem e marcam os corpos dos/as sujeitos/as.

Se levarmos em consideração os arranjos de gênero com outras marcas sociais (classe, raça, geração, religião, nacionalidade, identidades sexuais) teremos infinidades de apresentações. No campo da engenharia do corpo são estas infinidades de apresentações que se inscrevem as articulações entre gênero, sexualidade e as pedagogias, ampliando para além dos processos familiares e escolares a aprendizagem da sexualidade.

A partir desses cenários, deveríamos nos perguntar, antes de tudo, como determinadas características passaram a ser nomeadas e significadas como marcas de uma identidade ou de outra. Penso que apresentamos alguns caminhos que justificam algumas marcas do corpo, mas é importante destacar a necessidade de se aprofundar o conhecimento sobre as práticas pedagógicas que funcionam como verdades e modelam nossas subjetividades e formas de atuar no mundo.

\section{MARCIO RODRIGO VALE CAETANO}

Mestrado e doutorado em educação pela Universidade Federal Fluminense (UFF). Estágio, em nível de pós-graduação, no Programa de Estudios Feministas do Centro de Investigaciones Interdisciplinarias en Ciencias y Humanidades da Universidad 
Atos de Pesquisa em Educação - ISSN 1809-0354

Blumenau - vol. 11, n. 2, p.634-655 ago./nov. 2016

DOI: http://dx.doi.org/10.7867/1809-0354.2016v11n2p634-655

Nacional Autónoma de México (CEIICH- UNAM). Professor no Programa de PósGraduação em Educação da Universidade Federal do Rio Grande - FURG

\section{TREYCE ELLEN SILVA GOULART}

Doutoranda no Programa de Pós-graduação em Educação da Universidade Federal Fluminense. Mestre no Programa de Pós-Graduação em Educação da Universidade Federal do Rio Grande - FURG.

\section{MARLON SILVEIRA DA SILVA}

Mestrando pelo Programa de Pós-Graduação em Educação (PPGEdu) da Universidade Federal do Rio Grande (FURG)

\section{REFERÊNCIAS}

BRITZMAN. D. P. Educación precoz. In. STEINBERG, S.; TALBURT, S (eds). Pensando queer: sexualidad, cultura educación. Barcelona: Graó, 2005.

BRITZMAN. D. P. Curiosidade, Sexualidade e Currículo. In. LOURO, G. L. O corpo educado: pedagogias da sexualidade. Belo Horizonte, Autêntica, 2001.

BUTLER, J. Problemas de gênero: feminismo e subversão da identidade. RJ, Civilização Brasileira, 2003.

BUTLER, J. Variaciones sobre sexo y género. In. LAMAS, M. El género: la construcción cultural de la diferencia sexual. Ciudad de México- México: UNAMPUEG, 2003a. p.303-326.

CAETANO, M. Gênero e Sexualidade: um encontro político com as epistemologias de vida e os movimentos curriculares. 2011. 228f. Tese de doutorado. Programa de PósGraduação em Educação da Universidade Federal Fluminense do Rio de Janeiro, 2011.

CAETANO, M.; DE GARAY HERNANDEZ, J. Para além das dicotomias: Performances de gênero, sexualidades e questões à escola. Advir (ASDUERJ), v. 28, p. 38-53, 2012.

FOUCAULT, M. Vigiar e punir: nascimento da prisão. Petrópolis: Vozes, 1987. FOUCAULT, M. História da sexualidade - a vontade de saber. Rio de Janeiro: ED. Graal, 1988. Vol. 1. 
FOUCAULT, M. História da sexualidade - o uso dos prazeres. Rio de Janeiro: ED. Graal, 2006. Vol. 2.

FOUCAULT, M. História da sexualidade - o cuidado de si. Rio de Janeiro: ED. Graal, 2005. Vol. 3.

FOUCAULT, M. Resumo dos Cursos do Collège de France (1970-1982). Rio de Janeiro: Jorge Zahar, 1997.

FURLANI, J. O bicho vai pegar!Um olhar pós-estruturalista à Educação Sexual a partir de livros paradidáticos infantis. Tese (Doutorado em Educação). Universidade Federal do Rio Grande do Sul - UFRGS, Porto Alegre, 2005.

GOELLNER, S. A produção cultural do corpo. In: LOURO, GAUCIRA et al (Org.). Corpo, Gênero e Sexualidade: um debate contemporâneo na educação. 3 ed. Petrópolis: Vozes, 2007. p. 28-40.

HARAWAY, D. Manifesto ciborgue: ciência, tecnologia e feminismo socialista no final do século XX. In: SILVA, Tomaz (Org.). Antropologia do ciborgue: as vertigens do pós humano. Belo Horizonte: Autêntica, 2000.

HOOKS, B. Ensinando a transgredir. A educação como prática da liberdade. São Paulo: Editora WMF Martins Fontes, 2013.

LORDE, A. Usos do Erótico: O Erótico como poder. 1984. Disponível em $<$ https://traduzidas.files.wordpress.com/2013/07/traduzidas01_usos-doerc3b3tico_lorde.pdf>. Acesso em 13 jun. 2015.

LUGONES, M. Hacía um feminismo decolonial. La manzana de la discordia, Julio Diciembre, Año 2011, Vol. 6, No. 2: 105-119 Disponível em <http://manzanadiscordia.univalle.edu.co/volumenes/articulos/V6N2/art10.pdf>. Acesso em 13 jun. 2015.

MENDOZA, B. La epistemologia del sur, la colonialidad del género y el feminismo latino-americano. Disponível em <http://media.wlx.com/ugd/ 1f3b4c4b4fc9c69d30059e91571ae5c897dda7.pdf.> Acesso em 13 jun. 2015.

PINTO, M. da C. Um elogio ao ensaio. São Paulo: Ateliê Editorial, 1998.

QUIJANO, A. Colonialidade do poder, eurocentrismo e América Latina. In: A colonialidade do saber: eurocentrismo e ciências sociais. Perspectivas latinoamericanas. Edgardo Lander (org). Colección Sur Sur, CLACSO, Ciudad Autónoma de Buenos Aires, Argentina. Setembro 2005. 
Atos de Pesquisa em Educação - ISSN 1809-0354

Blumenau - vol. 11, n. 2, p.634-655 ago./nov. 2016

DOI: http://dx.doi.org/10.7867/1809-0354.2016v11n2p634-655

RANGEL, M. Ensaio sobre aplicações didáticas da teoria de representação social. Revista Olhar de Professor, vol. 10, núm. 2, 2007, pp. 11-22.

RUBIN, G. El tráfico de mujeres: notas sobre la "economía política" del sexo. Revista Nueva Antropología. Noviembre, año I Vol. VIII, n.o 30. UNAM, DF, México, 1975. pp. 95-145.

SILVA, T. T. da. Documentos de Identidade: uma introdução às teorias do currículo. Belo Horizonte: Autêntica, 1999.

WEEKS, J. Sexualidad. Ciudad de México: UNAM/PUEG/Paidós género y sociedad, 1998.

WITTIG, M. El pensamiento heterosexual y otros ensayos. Barcelona - España: Egales, 2006.

WITTIG, M. The Straight Mind: and other essays. Boston: Beacon Press, 1992.

Artigo recebido em junho de 2015. Aprovado em maio de 2016.

\section{(c) ${ }_{\mathrm{EY}}$}

Este trabalho está licenciado com uma Licença Creative Commons - Atribuição 4.0 Internacional 